\title{
KAJIAN PELAKSANAAN PRAKTIKUM ILMU PENGETAHUAN ALAM SEKOLAH MENENGAH PERTAMA DI KOTA MATARAM
}

\section{STUDY ON THE IMPLEMENTATION OF NATURAL SCIENCE PRACTICUM THE FIRST MIDDLE SCHOOL IN THE CITY OF MATARAM}

\author{
Aliefman Hakim, A. Wahab Jufri, Kosim, Imam Bactiar, Syamsul Bahri \\ Program Studi Magister Pendidikan IPA Universitas Mataram, Mataram, Indonesia. \\ Email: aliefmanhakim27@gmail.com
}

Diterima: 12 November 2019. Disetujui: 31 Desember 2019. Dipublikasikan: 2 Maret 2020

\begin{abstract}
Abstrak: Penelitian ini bertujuan untuk melakukan pemetaan terhadap aktivitas praktikum IPA di Sekolah Menengah Pertama (SMP) di Kota Mataram diantaranya adalah identifikasi tingkat motivasi guru-guru IPA SMP Negeri di Kota Mataram dalam melakukan kegiatan praktikum IPA, data pelaksanaan praktikum yang telah berlangsung dengan mengobservasi kendala yang ada termasuk kondisi sarana prasarana penunjang praktikum IPA di SMP di Kota Mataram. Penelitian ini merupakan penelitian survey dengan menggunakan metode fishbone diagram (diagram tulang ikan). Pengumpulan data pada survey dijaring menggunakan angket/kuisioner dan wawancara. Jenis kuisioner pada penelitian ini adalah kuisioer tertutup dengan rating scale. populasi penelitian ini berjumlah 24 sekolah negeri. Penentuan sampel dilakukan secara random sehingga diperoleh sampel guru IPA sebanyak 15 sampel. Sampel diberikan tiga jenis angket yaitu angket motivasi praktikum, angket pelaksanaan praktikum, dan angket sarana prasarana penunjang praktikum. Motivasi guru IPA dalam melakukan kegitan praktikum termasuk kategori sedang dengan rata-rata sebesar 64 yang terbagi dalam 13.3\% motivasi tinggi dan $86.7 \%$ motivasi sedang. Pelaksanaan praktikum IPA tergolong baik yaitu sebesar $80.3 \%$. Adapun ketersediaan saran prasarana penunjang praktikum tergolong sangat baik yaitu sebesar $94.2 \%$ tersedia. Akan tetapi, berdasarkan hasil hasil uji regresi linear dengan nilai signifikansi 0.355 lebih besar dari 0.05 . Hal ini menunjukkan bahwa motivasi praktium, pelaksanaan praktikum, dan ketersediaan sarana prasarana tidak saling berhubungan.
\end{abstract}

Kata kunci: Pembelajaran IPA, Motivasi Praktikum IPA, Pelaksanaan praktikum IPA, Ketersediaan sarana prasarama penunjang praktikum, fishbone diagram.

\begin{abstract}
This study aims to map the science practice activities in junior high schools in the city of Mataram including identification of the level of motivation of state junior high school science teachers in the city of Mataram in carrying out science practice activities, data on the implementation of practicums that have taken place by observing constraints that including the condition of the infrastructure facilities to support the science practice in junior high schools in the city of Mataram. This research is a survey research using the fishbone diagram method. Data collection in surveys was collected using questionnaires and interviews. The type of questionnaire in this study is a closed quisioer with a rating scale. This study population totaled 24 public schools. Sampling was done randomly so that 15 samples of science teachers were obtained. The sample was given three types of questionnaires, namely practicum motivation questionnaire, practicum questionnaire, and questionnaire for supporting facilities for practicum. Motivation of science teachers in practicing practicum is included in the medium category with an average of 64 which is divided into $13.3 \%$ high motivation and $86.7 \%$ moderate motivation. The IPA practicum is classified as good at $80.3 \%$. The availability of suggestions for supporting infrastructure for practicum is very good, namely $94.2 \%$ available. However, based on the results of the linear regression test with a significance value of 0.355 greater than 0.05 . This shows that practical motivation, practicum implementation, and availability of infrastructure are not interconnected.
\end{abstract}

Keywords: Science Learning, Motivation of Science Practicum, Science Practicum Implementation, Availability of practical facilities supporting practicum, Fishbone diagram.

\section{PENDAHULUAN}

Ilmu IPA adalah ilmu yang berbasis teori dan ekperimen [1]. Kajian IPA berupa teori dapat dibuktikan kebenarannya melalui pengalaman praktikum, sedangkan praktikum akan dapat dilaksanakan dengan baik dan benar jika dilandasi dengan teori [2]. Jika dalam proses pembelajaran IPA hanya didominasi oleh teori tanpa adanya praktek maka dapat disimpulkan bahwa tingkat pemahaman siswa pada materi tersebut masih kurang optimal [3]. Selain itu, proses pembelajaran IPA yang hanya menekankan pada teori saja tanpa praktek akan cenderung membosankan, kurang diminati dan akhirnya siswa menganggap bahwa pelajaran IPA itu sulit. Selanjutnya banyaknya konsep IPA yang bersifat abstrak yang harus diserap siswa dalam waktu relatif terbatas menyebabkan banyak siswa gagal dalam belajar IPA [4]. Oleh sebab itu butuh sinkronisasi antara pembelajaran 
teori dan praktek terutama pada pembelajaran IPA di SMP.

Mempelajari ilmu IPA bukan hanya menguasai kumpulan pengetahuan berupa fakta, konsep, atau prinsip saja tetapi dapat berupa suatu proses penemuan, proses membangun konsep, mengkomunikasikan berbagai fenomena yang terjadi, dan penguasaan metode ilmiah [5].

Metode pembelajaran yang kini masih banyak diterapkan oleh guru di sekolah adalah metode ceramah. Proses pembelajaran dengan menggunakan metode ceramah cenderung menjadikan siswa pasif karena guru berkedudukan sebagai pusat perhatian siswa dalam kelas dan siswa hanya sebagai pendengar tanpa diberi kesempatan untuk terlibat langsung dalam aktivitas pembelajaran, sehingga menyebabkan minat dan motivasi siswa dalam belajar IPA menjadi rendah. Akibatnya prestasi belajar siswa pun menjadi rendah.

Pembelajaan IPA di SMP sangat membutuhkan strategi pembelajaran yang tepat. Maksudnya adalah agar diciptakan suasana pembelajaran yang memungkinkan siswa untuk terlibat secara aktif dalam menemukan konsep materi yang sedang dipelajarinya. Mereka diberi kesempatan dan difasilitasi untuk mencerna dan mengolah informasi (fenomena) yang diterima secara optimal baik sisi teori maupun praktik. Maka untuk optimalisasi hasil pembelajaran selain diberikan konsep-konsep IPA yang tepat maka siswa juga harus dilibatkan dalam kegiatan praktikum untuk dapat mengetahui proses-proses IPA yang terjadi secara lebih riil.

Hal ini senada dengan tujuan mata pelajaran IPA di SMP/MA yaitu agar peserta didik memiliki kemampuan: (1) membentuk sikap positif terhadap IPA dengan menyadari keteraturan dan keindahan alam serta mengagungkan kebesaran Tuhan Yang Maha Esa; (2) memupuk sikap ilmiah yaitu jujur, objektif, terbuka, ulet, kritis, dan dapat bekerjasama dengan orang lain; (3) memperoleh pengalaman dalam menerapkan metode ilmiah melalui percobaan atau eksperimen, dimana peserta didik melakukan pengujian hipotesis dengan merancang percobaan melalui pemasangan instrumen, pengambilan, pengolahan dan penafsiran data, serta menyampaikan hasil percobaan secara lisan dan tertulis; (4) meningkatkan kesadaran tentang terapan IPA yang dapat bermanfaat dan juga merugikan bagi individu, masyarakat, dan lingkungan serta menyadari pentingnya mengelola dan melestarikan lingkungan demi kesejahteraan masyarakat; dan (5) memahami konsep, prinsip, hukum, dan teori IPA serta saling keterkaitannya dan penerapannya untuk menyelesaikan masalah dalam kehidupan sehari-hari dan teknologi [6].

Pelaksanaan praktikum IPA pada tingkat SMP memiliki tantangan tersendiri. Selain tingkat kemampuan guru serta motivasi yang dimiliki guru untuk melaksanakan kegiatan praktikum IPA, faktor ketersediaan sarana dan prasarana penunjang kegiatan praktikum IPA juga sangat menentukan keberlangsungan kegiatan praktikum. Tantangan lain adalah ketersediaan anggaran yang memadai terutama untuk pembelian bahan-bahan IPA serta peralatan habis pakai lainnya. Selanjutnya tingkat resiko atau keselamatan kerja dalam pelaksanaan praktikum juga menjadi faktor penentu berlangsungnya kegiatan praktikum.

Ilmu IPA terdapat dua hal yang sangat berkaitan dan tidak dapat dipisahkan, yaitu ilmu IPA sebagai produk (pengetahuan IPA berupa fakta, konsep, teori, dan prinsip) dan proses (kerja ilmiah) [7]. Kedua hal tersebut dapat dicapai peserta didik salah satunya melalui kegiatan praktikum [2][12]. Praktikum merupakan strategi pembelajaran atau bentuk pengajaran yang digunakan untuk membelajarkan secara bersama-sama kemampuan psikomotorik (keterampilan), kognitif (pengetahuan), dan afektif (sikap) menggunakan sarana laboratorium [12].

Kegiatan praktikum IPA di sekolah tidak terlepas dari berbagai kendala. Tidak semua SMP memiliki laboratorium yang memadai. Selain itu, alat dan bahan yang diperlukan kadang-kadang sulit dipenuhi oleh sekolah [8]. Berdasarkan hasil studi lapangan guru di Indonesia masih kurang memanfaatkan kegiatan praktikum sebagai salah satu kegiatan dalam proses belajar mengajar [9]. Kondisi ini disebabkan oleh beberapa hal seperti: 1) Keterampilan guru dalam pelaksanaan kegiatan praktikum dan penggunaan; 2) alat kurang optimal; 3) Petunjuk praktikum yang belum baku sehingga berbeda-beda antar sekolah; 4) Peralatan praktikum yang tersedia tidak mencukupi dari jumlah idealnya bahkan ada yang tidak memilikinya; 5) Kesulitan dalam pengadaan bahan yang diperlukan praktikum; 6) Minimnya tenaga laboran di sekolah, sehingga guru harus bekerja sendiri dalam mempersiapkan praktikum; 7) Alokasi waktu untuk melaksanakan praktikum masih kurang; 8) Pemahaman mengenai pentingnya praktikum dalam mengaplikasikan sains masih kurang.

\section{METODE PENELITIAN}

Penelitian ini merupakan penelitian jenis survey dengan menggunakan metode fishbone diagram. Masalah akan dipecah menjadi sejumlah kategori yang berkaitan, mencakup sumber daya manusia, Sarana dan prasarana penunjang, Prosedur, motivasi, dan sebagainya [10]. Setiap kategori mempunyai sebab-sebab yang perlu diuraikan melalui sesi brainstorming.

Populasi dalam penelitian ini adalah seluruh guru IPA di SMP Negeri Se Kota Mataram yang terdiri dari 24 sekolah. Sampel pada penelitian ini adalah seluruh guru IPA SMP Negeri se Kota Mataram. 
Pada penelitian ini pengambilan data menggunakan kuisioner. Jenis kuisioner pada penelitian ini adalah kuisioner tertutup dengan rating scale. Data hasil penelitian survei dianalisis menggunakan teknik deskriptif kuantitatif berupa persentase sederhana, penggunaan tabel, dan gambar. Untuk interpretasi data permasalahan dan kebutuhan menggunakan kriteria: sangat baik, jika $p k>80$ persen; baik, jika 60 persen $<p k \leq 80$ persen; sedang/cukup, jika 40 persen $<p k \leq 60$ persen; kurang, jika 20 persen $<p k \leq 40$ persen; sangat kurang $p k<20$ persen, dimana $p k$ merupakan komponen permasalahan dan kebutuhan kegiatan praktikum. Selanjutnya dilakukan uji regresi linear melihat apakah ada hubungan antara motivasi, pelaksanaan, dan ketersediaan sarana dan prasarana penunjang praktikum.

\section{HASIL DAN PEMBAHASAN}

Tingkat Motivasi Guru IPA Melaksanakan kegiatan Praktikum di SMPN Se Kota Mataram

Berdasarkan data pada tabel 1 dapat diketahui bahwa motivasi guru melaksanakan kegiatan praktikum adalah 2 sekolah dengan Motivasi Tinggi (13.3\%), 13 sekolah dengan Motivasi Sedang (86.7\%). Secara rata-rata tingkat motivasi melaksanakan kegiatan praktikum di sekolah SMPN se Kota Mataram memiliki rata-rata sebesar 64 yang termasuk dalam kategori sedang.

Ada beberapa hal yang menyebabkan tngkat motivasi tidak mencapai persentase maksimal yaitu terbatasnnya waktu pembelajaran. Dalam proses praktikum membutuhkan waktu yang panjang. Seperti hasil angket yang diisi oleh guru IPA, kendala praktikum rata-rata adalah pada alokasi waktu pembelaaran yang tidak sesuai. Adapun faktor lain yang butuh perhatian khusus dalam pelaksanaan praktikum adalah adanya pemikiran dalam diri seorang guru bahwa praktikum bisa digantikan oleh sebuah demonstrasi di depan kelas. Pemikiran ini harus dibersihkkan dalam diri seorang guru karena demonstrasi tidak menciptakan suatu pembelajaran yang aktif. Dengan demikian siswa tidak maksimal dalam menerima informasi yang disampaikan.

\section{Keadaan Sarana dan Prasarana Laboratorium}

Sarana dan sarana penunjang laboratorium adalah faktor yang paling penting dalam proses pelaksanaan praktikum dalam pembelajaran. Semua proses pembelajaran berbasis praktikum atau penemuan membutuhkan sarana penunjang. Kebradaan peralatan, bahan, ruang laboratorium, dan SDM pengelola laboratorium yang memadai

Berdasarkan data yang disajikan diatas secara keseluruhan menunjukkan bahwa sarana dan prasarana laboratorium di SMPN Se Kota Mataram masuk kategori Sangat Baik (94.2\%). Ruang laboratorium sangat baik (98.3\%), Sarana dalam tuang laboratorium sanagat baik (97\%), Namun SDM Pengelola laboratorium tergolong baik
(62.2\%). Hal ini disebabkan semua sekolah tidak memiliki SDM Pengelola Laboratorium lebih dari satu. Banyaknya materi pelajaran yang memungkin untuk praktikum tidak bisa terlaksana disebabkan minimnya tenaga pengelola laboratorium. Di sekolah-sekolah belum ada pembagian tugas yang spesifik dalam penanganan laborattorium. Semua dikendalikan oleh seorang laboran.

\section{Pelaksanaan Praktikum di SMPN se Kota Mataram}

Keberadaan sarana dan prasarana pendukung yang memadai dan didorong motivasi guru IPA untuk melaksanakan kegiatan praktikum akan mensukseskan proses pelaksanaan kegitan praktikum di sekolah.

Berdasarkan data yang disajikan diatas menunjukkan bahwa keterlaksanaan praktikum, relevansinya dengan materi ajar serta keberhasilan pelaksanaan praktikum di SMPN Se Kota Mataram masuk kategori Sangat Baik 4 sekolah (26.7\%), Baik 11 sekolah (73.3\%). Secara rata-rata nilai pelaksanaan praktikum, relevansinya dengan materi ajar serta keberhasilan pelaksanaan praktikum di SMPN se Kota Mataram memiliki rata-rata $80.3 \%$ yang termasuk dalam kategori Sangat Baik.

\section{Korelasi antara Sarana dan prasarana laboratorium, Motivasi Melaksanakan Praktikum terhadap Pelaksanaan Praktikum di Sekolah}

Motivasi guru untuk melakukan kegiatan praktikum cukup tinggi yang dilihat dari persentase mencapai $76.67 \%$ yang didukung tersedianya sarana prasarana penunjang yang mencapai $94.17 \%$ tersedia. Dengan demikian, pelaksanaan praktikum IPA di Kota Mataram sudah berjalan mencapai $80.28 \%$ (gambar 1). Tingginya persentase tidak menjamin ada kerkaitan yang signifkan antara motivasi, pelaksanaan, dan sarana prasarana penunjang praktikum. Hal ini dapat dilihat pada tabel 5 dan tabel 6.

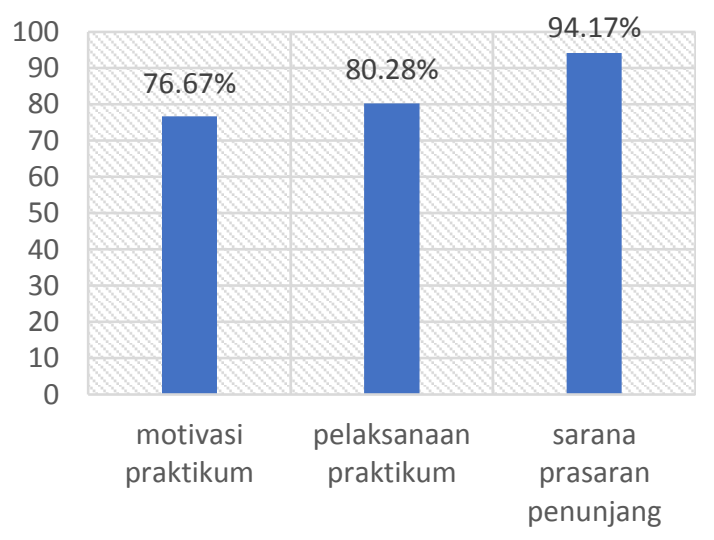

Gambar 1. Persentase Motivasi praktikum, Pelaksanaan praktikum, dan Sarana dan prasarana penunjang praktikum. 
Korelasi antara Sarana dan Prasarana Laboratorium dengan Pelaksanaan Kegiatan Praktikum memiliki nilai koefisien korelasi pearson 0,105 (sangat rendah) dengan tingkat signifikansi yang lebih besar $(0,708)$ dari 0,05 . Hal ini menunjukkan bahwa antara Sarana dan Prasarana Laboratorium dengan Pelaksanaan Kegiatan Praktikum di SMPN se Kota Mataram tidak mempunyai hubungan yang erat. Hal ini dapat diartikan bahwa meskipun Keberadaan Sarana dan Prasarana Laboratorium yang baik akan tetapi tidak ada jaminan keberlangsungan kegiatan pelaksanaan praktikum di sekolah dapat dilakukan.

Berdasarkan hasil analisis statistik pada tabel 5 juga menyimpulkan korelasi antara Motivasi guru untuk melaksanakan praktikum dengan Pelaksanaan Kegiatan Praktikum dengan sebesar 0,331 (rendah). Korelasi tersebut menunjukkan bahwa antara Motivasi guru untuk melaksanakan praktikum dengan Pelaksanaan Kegiatan Praktikum tidak saling berkorelasi.

Data di atas didukung oleh hasil uji regresi linear yang tercantum pada pada tabel 6 , diperoleh nilai signifikansinya sebesar 0,335 lebih besar dari 0,05 artinya antara Sarana dan Prasarana Laboratorium dan Motivasi Pelaksanaan Praktikum tidak berhubungan secara simultan dan signifikan terhadap Pelaksanaan Praktikum di Sekolah.

Hal ini diduga disebabkan karena beberapa faktor diantaranya: a). Materi pembelajaran di sekolah yang jumlahnya banyak menyebabkan tidak mungkin dilakukan praktikum seluruhnya, b). Keberadaan buku panduan praktikum di sekolah belum memadai atau tidak sesuai dengan kebutuhan praktikum, c). Kemampuan guru dalam menghubungkan antara materi pembelajaran teoritis untuk dipraktikumkan relatif masih kurang sehingga pelaksanaan kegiatan praktikum dianggap hanya formalitas saja, e). Kemampuan guru mengelola kegiatan praktikum masih kurang sehingga guru sendiri tidak yakin dengan apa yang harus dilakukan dalam praktikum tersebut, serta f). Rendahnyanya SDM pengelola laboratorium yaitu hanya mencapai $62.2 \%$. Oleh karena alasan-alasan tersebut di atas maka dianggap perlu dilakukan tindakan perbaikan terutama berkaitan dengan mengubah persepsi guru terhadap pelaksanaan praktikum disekolah misalnya adanya pelatihan manajemen laboratorium, standarisasi prosedur praktikum, pelatihan penggunaan alat-alat dan penanganan bahan praktikum, dan meningkatkan SDM pengelola laboratorium [13].

Tabel 1. Motivasi guru dalam melaksanakan praktikum

\begin{tabular}{|c|c|c|c|}
\hline \multirow{2}{*}{ No } & \multirow{2}{*}{ NAMA SEKOLAH } & \multicolumn{2}{|c|}{ Motivasi Guru Melaksanakan Praktikum } \\
\hline & & Motivasi (M) & Kriteria \\
\hline 1 & SMP Negeri 7 Mataram & 72 & Tinggi \\
\hline 2 & SMP Negeri 8 Mataram & 63 & Sedang \\
\hline 3 & SMP Negeri 10 Mataram & 54 & Sedang \\
\hline 4 & SMP Negeri 1 Mataram & 64 & Sedang \\
\hline 5 & SMP Negeri 19 Mataram & 59 & Sedang \\
\hline 6 & SMP Negeri 4 Mataram & 63 & Sedang \\
\hline 7 & SMP Negeri 16 Mataram & 61 & Sedang \\
\hline 8 & SMP Negeri 6 Mataram & 63 & Sedang \\
\hline 9 & SMP Negeri 17 Mataram & 64 & Sedang \\
\hline 10 & SMP Negeri 14 Mataram & 66 & Sedang \\
\hline 11 & SMP Negeri 3 Mataram & 67 & Sedang \\
\hline 12 & SMP Negeri 9 Mataram & 67 & Sedang \\
\hline 13 & SMP Negeri 11 Mataram & 70 & Tinggi \\
\hline 14 & SMP Negeri 20 Mataram & 67 & Sedang \\
\hline 15 & SMP Negeri 2 Mataram & 66 & Sedang \\
\hline & Rata-rata & 64 & \\
\hline & Standar Deviasi (SD) & 4.4 & \\
\hline & (Rata-rata + 1SD) & 68.79 & \\
\hline & (Rata-rata-1SD) & 60.01 & \\
\hline
\end{tabular}

Keterangan:

Keterangan : $\quad M=$ Tingkat Motivasi $\quad$ SD = Standar Deviasi

Kriteria :

$$
\begin{aligned}
& \mathrm{M}>(\text { Rata-rata }+1 \mathrm{SD}) \quad=\text { Tinggi } \\
& (\text { Rata-rata }-1 \mathrm{SD}) \leq \mathrm{M} \leq(\text { Rata-rata }+1 \mathrm{SD})=\text { Sedang } \\
& \mathrm{M}<(\text { Rata-rata }-1 \mathrm{SD}) \quad=\text { Rendah }
\end{aligned}
$$


Tabel 2. Keadaan Sarana dan Prasarana Laboratorium

\begin{tabular}{clrrrrrr}
\hline \multirow{2}{*}{ No } & \multirow{2}{*}{ NAMA SEKOLAH } & \multicolumn{5}{c}{ Sarana dan Prasarana Laboratorium } \\
\cline { 3 - 7 } & & K1 & K2 & K3 & Jumlah & \multicolumn{1}{c}{$\%$} & Kriteria \\
\hline 1 & SMP Negeri 7 Mataram & 4 & 22 & 2 & 28 & 87.5 & SB \\
2 & SMP Negeri 8 Mataram & 4 & 24 & 2 & 30 & 93.75 & SB \\
3 & SMP Negeri 10 Mataram & 4 & 25 & 2 & 31 & 96.875 & SB \\
4 & SMP Negeri 1 Mataram & 4 & 25 & 2 & 31 & 96.875 & SB \\
5 & SMP Negeri 19 Mataram & 4 & 23 & 2 & 29 & 90.625 & SB \\
6 & SMP Negeri 4 Mataram & 4 & 25 & 1 & 30 & 93.75 & SB \\
7 & SMP Negeri 16 Mataram & 4 & 25 & 1 & 30 & 93.75 & SB \\
8 & SMP Negeri 6 Mataram & 4 & 25 & 2 & 31 & 96.875 & SB \\
9 & SMP Negeri 17 Mataram & 4 & 23 & 2 & 29 & 90.625 & SB \\
10 & SMP Negeri 14 Mataram & 4 & 25 & 2 & 31 & 96.875 & SB \\
11 & SMP Negeri 3 Mataram & 3 & 23 & 2 & 28 & 87.5 & SB \\
12 & SMP Negeri 9 Mataram & 4 & 25 & 2 & 31 & 96.875 & SB \\
13 & SMP Negeri 11 Mataram & 4 & 25 & 2 & 31 & 96.875 & SB \\
14 & SMP Negeri 20 Mataram & 4 & 25 & 2 & 31 & 96.875 & SB \\
& & 4 & 25 & 2 & 31 & 96.875 & \\
\hline & Rerata & 3.93 & 24 & 1.87 & 30.13 & 94.2 & \\
& Persentase (\%) & 98.3 & 97 & 62.2 & 94.2 & & \\
\hline
\end{tabular}

Tabel 3. Pelaksanaan praktikum dan kesesuaian materi praktikum

\begin{tabular}{clcccccc}
\hline \multirow{2}{*}{ No } & \multirow{2}{*}{ NAMA SEKOLAH } & \multicolumn{5}{c}{ Pelaksanaan Praktikum } \\
\cline { 3 - 7 } & & P1 & P2 & P3 & Jumlah & $\%$ & Kriteria \\
\hline 1 & SMP Negeri 7 Mataram & 10 & 5 & 9 & 24 & 100 & SB \\
2 & SMP Negeri 8 Mataram & 10 & 4 & 7 & 21 & 87.5 & SB \\
3 & SMP Negeri 10 Mataram & 8 & 3 & 8 & 19 & 79.2 & B \\
4 & SMP Negeri 1 Mataram & 10 & 4 & 8 & 22 & 91.7 & SB \\
5 & SMP Negeri 19 Mataram & 9 & 2 & 5 & 16 & 66.7 & B \\
6 & SMP Negeri 4 Mataram & 9 & 2 & 8 & 19 & 79.2 & B \\
7 & SMP Negeri 16 Mataram & 9 & 2 & 7 & 18 & 75 & B \\
8 & SMP Negeri 6 Mataram & 9 & 3 & 9 & 21 & 87.5 & SB \\
9 & SMP Negeri 17 Mataram & 8 & 2 & 7 & 17 & 70.8 & B \\
10 & SMP Negeri 14 Mataram & 10 & 2 & 8 & 20 & 83.3 & SB \\
11 & SMP Negeri 3 Mataram & 6 & 3 & 8 & 17 & 70.8 & B \\
12 & SMP Negeri 9 Mataram & 8 & 3 & 8 & 19 & 79.2 & B \\
13 & SMP Negeri 11 Mataram & 9 & 1 & 8 & 18 & 75 & B \\
14 & SMP Negeri 20 Mataram & 8 & 3 & 8 & 19 & 79.2 & B \\
& & 8 & 3 & 8 & 19 & 79.2 & B \\
\hline & Rerata & 8.73 & 2.8 & 7.73 & 19.3 & 80.3 & \\
& Persentase (\%) & 87.3 & 56 & 85.9 & 80.3 & & \\
\hline
\end{tabular}

$\begin{array}{llll}\text { Keterangan: } & \text { P1 } & =\text { Pelaksanaan Praktikum }(10 \text { item }) \\ & \text { P2 } & =\text { Relevansi dengan Materi Ajar }(5 \text { item }) \\ & \text { P3 } & =\text { Keberhasilan Pelaksanaan Praktikum }(9 \text { item }) \\ \text { Kriteria: } & \text { SB } & =\text { Sangat Baik } & (>80 \%) \\ & \text { B } & =\text { Baik } & (60<\mathrm{KR} \leq 80) \\ & \text { C } & =\text { Cukup } & (40<\mathrm{KR} \leq 60)\end{array}$


Tabel 5. Hasil anasisis statistik korelasi Pearson antara Sarana dan prasarana laboratorium, Motivasi Melaksanakan Praktikum terhadap Pelaksanaan Praktikum sebagai berikut:

\begin{tabular}{|c|c|c|c|c|}
\hline & & $\begin{array}{l}\text { Motivasi } \\
\text { praktikum }\end{array}$ & $\begin{array}{c}\text { Pelaksanaan } \\
\text { Praktikum }\end{array}$ & $\begin{array}{l}\text { Kelengkapan } \\
\text { Laboratorium }\end{array}$ \\
\hline & Pearson & 1 & .331 & -.185 \\
\hline Motivasi & Correlation & & & \\
\hline \multirow[t]{3}{*}{ praktikum } & Sig. (2-tailed) & & .228 & .509 \\
\hline & $\mathrm{N}$ & 15 & 15 & 15 \\
\hline & Pearson & .331 & 1 & .105 \\
\hline Pelaksanaan & Correlation & & & \\
\hline \multirow[t]{3}{*}{ Praktikum } & Sig. (2-tailed) & .228 & & .708 \\
\hline & $\mathrm{N}$ & 15 & 15 & 15 \\
\hline & Pearson & -.185 & .105 & 1 \\
\hline Kelengkapan & Correlation & & & \\
\hline \multirow[t]{2}{*}{ Laboratorium } & Sig. (2-tailed) & .509 & .708 & \\
\hline & $\mathrm{N}$ & 15 & 15 & 15 \\
\hline
\end{tabular}

Sumber: Pengolahan Data Sekunder

Kriteria korelasi pearson:

$$
\begin{array}{lll}
0 & -0,20 & =\text { Sangat Rendah (hampir tidak ada hubungan) } \\
0,21- & -0,40 & =\text { Rendah } \\
0,41-0,60 & =\text { Sedang } \\
0,61-0,80 & =\text { Cukup Tinggi } \\
0,81-1 & =\text { Tinggi }
\end{array}
$$

\begin{tabular}{|c|c|c|c|c|c|c|}
\hline \multicolumn{7}{|c|}{ ANOVA $^{a}$} \\
\hline Model & & Sum of Squares & $\mathrm{df}$ & Mean Square & $\mathrm{F}$ & Sig. \\
\hline \multirow{3}{*}{1} & Regression & 42.700 & 2 & 21.350 & 1.129 & $.355^{\mathrm{b}}$ \\
\hline & Residual & 226.900 & 12 & 18.908 & & \\
\hline & Total & 269.600 & 14 & & & \\
\hline $\begin{array}{l}\text { a. Dep } \\
\text { b. Pred }\end{array}$ & $\begin{array}{l}\text { dent Variab } \\
\text { tors: (Const }\end{array}$ & $\begin{array}{l}\text { Iotivasi } \\
\text { Pelaksanaan, Sa }\end{array}$ & rasaran & & & \\
\hline
\end{tabular}

Tabel 6. Hasil analisis korelasi berganda Sarana dan Prasaran Laboratorium, Motivasi Melaksanakan Praktikum dengan Pelaksanaan Praktikum di sekolah menggunakan SPSS sebagai beikut:

\section{KESIMPULAN}

Motivasi praktikum, pelaksaan praktikum, dan ketersediaan sarana prasarana di SMPN se Kota Mataram secara keseluruhan tergolong baik yaitu dengan presentase berturut-turut $76.67 \%$ (baik), $80.28 \%$ (baik), $94.17 \%$ (sangat baik). Namun motivasi praktikum, pelaksanaan praktikum, dan keteserdiaan sarana prasarana tidak saling berkorelasi dengan nilai 0.335 lebih besar dari 0.05 .

\section{DAFTAR PUSTAKA}

[1] HAKIM, A., \& JUFRI, A. W. (2018). Natural products laboratory project: Isolation and structure elucidation of piperin from piper nigrum and andrographolide from Andrographis paniculata. Journal of Turkish Science Education, 15(4), 15-28.

[2] Hakim, A., Kadarohman, A., \& Syah, Y. M. (2016). Making a natural product chemistry course meaningful with a mini project laboratory. Journal of Chemical Education, 93(1), 193-196.

[3] HAKİM, A., KADAROHMAN, A., \& SYAH, Y. M. (2016). Effects of the natural product mini project laboratory on the students conceptual understanding. Journal of Turkish Science Education, 13(2), 27-36.

[4] Hakim, A., Liliasari, L., Kadarohman, A., \& Syah, Y. M. (2016). Improvement of student critical thinking skills with the natural product mini project laboratory learning. Indonesian Journal of Chemistry, 16(3), 322-328.

[5] Jahro, I. S. (2009). Analisis Penerapan Metode Praktikum pada Pembelajaran Ilmu Kimia di Sekolah Menengah Atas. /, 20-26.

[6] PERTAMA, S. M. (2006). Model Kurikulum Tingkat Satuan Pendidikan.

[7] Pendidikan, P. P. K. T. S., \& Menengah, D. (2006). Badan Standar Nasional Pendidikan.

[8] Salirawati, D. (2011). Materi Pelatihan Kepala Laboratorium Kimia bagi Guru-Guru Kimia Kabupaten Kulon Progo. Disampaikan di Laboratorium FMIPA UNY Yogyakarta, 1.

[9] Hadi, A. (2009). Upaya Mengatasi Keterbatasan Pelaksanaan Praktikum Kimia di SMA/MA Melalui Pengembangan Alat Peraga Praktikum Kimia Skala Kecil Skripsi Inst. Teknol. Bandung. 
[10] Arikunto, S. (2006). Penelitian suatu pendekatan praktek. Jakarta: Rineka Cipta.

[11]Ningsyih, S., Junaidi, E., \& Al Idrus, S. W. (2016). Pengaruh Pembelajaran Praktikum Berbasis Inkuiri Terbimbing Terhadap Kemampuan Berpikir Kritis Dan Hasil Belajar Kimia Siswa. Jurnal Pijar Mipa, 11(1).

[12]Zainuddin, M. (2001). MengajarPraktikum. PAU-PPAI Universitas Terbuka. Jakarta.
[13] Makhrus, M., \& Wahyudi, W. (2011). PENGARUH PEMBERIAN DESAIN PRALAB TERHADAP KEMAMPUAN MAHASISWA DALAM MEMAHAMI KONSEP HUKUM II NEWTON TENTANG GERAK. Jurnal Pijar Mipa, 6(1). 